\title{
From Single Enterprises to Complementary Networks
}

\author{
E.h. Hans-Peter Wiendahl, Arne Engelbrecht, Oliver Hamacher \\ Institute of Production Systems, University of Hanover, Germany \\ Email: hamacher@ifa.uni-hannover.de
}

Keywords Virtual enterprises, production networks, added value networks, complementary competencies, mass customization

\begin{abstract}
Modern information infrastructure systems have strong effects on world wide operating enterprises, simplifying the access to global markets on the one hand and leading to a harder competition between enterprises offering similar products or services on the other. Additionally, the society of today asks for stronger customized products which cannot be produced economically with conventional production methods. In this context the early outmaking of upcoming needs of the society and their quick satisfaction with tailor-made products and services are future key factors to business success. Especially for small and medium enterprises the collaboration with partners possessing complementary competencies in so-called Complementary Networks offers a unique method for reaching this objective. The combination of complementary products and services adds to the value appreciated by the customer and opens new business fields and/or improves the market positions for the enterprises. This paper gives a brief description of the individual phases for the establishment and operation of these networks with practical examples showing the enormous potentials of Complementary Networks.
\end{abstract}

\section{INTRODUCTION}

The ongoing globalization process driven by the development of modern infrastructure systems has changed the local and global environment of producing enterprises dramatically. More and more rival companies are pushing into the existing markets, leading a strong price and performance competition. Improved productivity of up to double percentage figures by leading companies is characteristic of the challenges. The long-term result of the accompanying intensive automation in the industrial sector is that the 
requisite quantity of goods can be produced with ever fewer workers. The resulting products, in many cases with exchangeable functional features, mean that it is becoming more and more difficult to achieve cost advantages through more economical production [1].

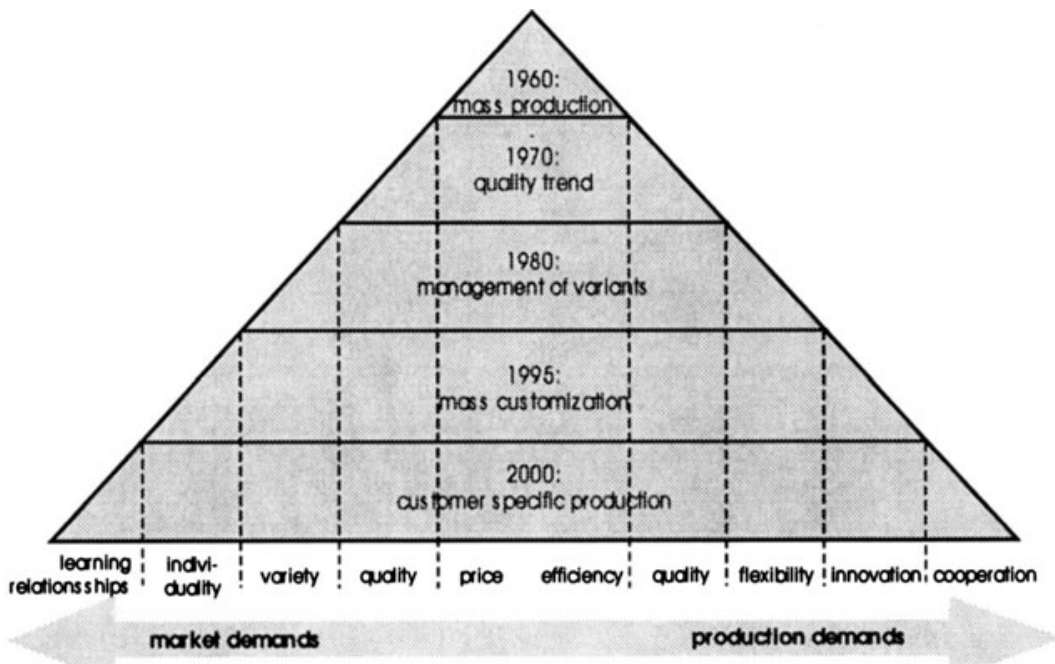

Figure 1: Increasing market demands require higher production demands [Piller]

Additionally the demands of the market rapidly change and increase (Fig. 1). In the industrial age customers were easy to satisfy with standardized and bulk products which were sold from stock. With the growing needs of the society, enterprises had to deal with a rising number of variants in the production and a higher complexity of the products.

\section{NEW PRODUCTION STRATEGIES}

These tightened circumstances force enterprises to find new strategies for realizing efficiency and individualization simultaneously. More and more enterprises today discover the Mass Customization as a unique way of combining the advantages of the cost reduction and the differentiation strategy, instead of trying to marginally improve their productivity. Mass Customization is defined as a production of large quantities with a strong customer focus to fulfill individual needs and demands, without a loss of production efficiency [2]. By tailoring fixed product elements to individual customer needs a maximum degree of product specific individualization can be achieved. In this context so-called "learning relationships" are of great importance, giving the enterprise a much better understanding of the customers needs as the relationship goes on. 
On the other hand customers are always forced to choose from a fixed number of possible product variants which might only be a compromise between their true needs and the available product on the market. This is the approach for the customer specific production, where the customers describe their individual problem and then receive a unique manufactured solution for solving it. Such products, however, provide the opportunity not only for large enterprises but also for small and medium enterprises (SME) to differentiate themselves from their competitors.

portfolio of the enterprise

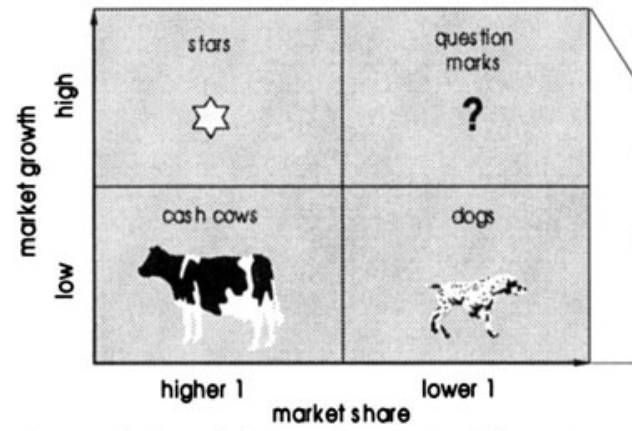

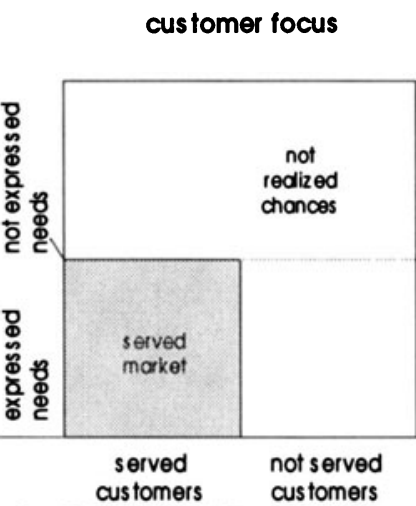

Figure 2: Possibilities of strategic differentiation for SME [BCG / Prahalad]

With their quest for customer orientation many enterprises merely use the potential of the market (Fig. 2). Since customers are generally remarkable for a notorious lack of far-sightness, only the articulated needs of the customers are served in the respective market segment [3].

There is often a failure to see the opportunities in the new business fields that can be purposefully opened up by focusing on a potential customer value outside the market segment. In one example, a large American automobile concern suffered an instructive experience when an assessment of the articulated needs of its regular customers did not lead to the desired success. A small family car was introduced in 1991 after a five-year development project. The design and specifications of the car were the result of the most intensive questioning of its customers that the firm had ever conducted. The problem emerged, however, that the newly produced car was extraordinarily similar to the three-year-old rival Japanese model. The customers had only formulated what was already known to them. Akio Morita, the visionary founder of Sony, put it as follows [3]: "Our plan is to lead the consumer to new products rather than to ask them what sort of products they want. The customers don't know what is possible - we do."

The not realized chances (blind spots) can be opened up through new core competencies which have the same customer value. SME cannot fulfil 
these requirements as easily as large enterprises because they seldom have sufficient R\&D capacities at their disposal. One way of compensating for this deficit, however, is by teaming up with partners who already possess the requisite (complementary) core competencies [4].

Decisive success factors for SME therefore include adaptability, efficient structures and the management of relationships to other organizations leading to a common competence to open up new fields of business through the customized individualization of products and services. The only firms to survive will be those that recognize or generate new market needs in good time and quickly convert them into products and services tailored to individual customers with their specific partners [5].

\section{DESIGN OF COMPLEMENTARY NETWORKS}

\subsection{Basic Structure of a Virtual Enterprise}

Virtual Enterprises are praised to be the ideal organization structure for cooperation in the future [6]. They combine the adaptability of small units with the synergy effects of large organizations and build up on the idea to combine certain process units benefiting from synergy effects for the time of a specific project. This can lead to the extreme of pursuing only a single business idea, exploiting it and then splitting up again - an temporary enterprise which defines itself by its specific linking [7].

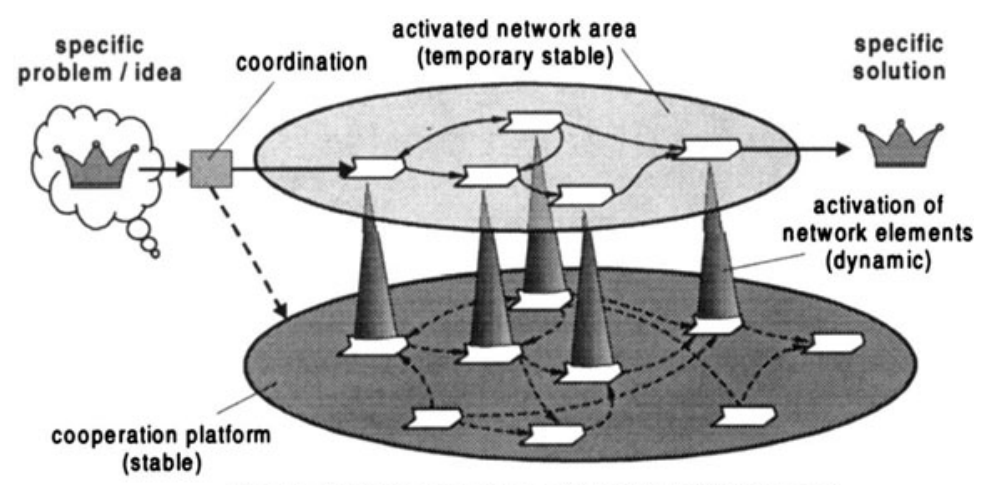

Figure 3: Basic structure of a Virtual Enterprise

Starting up a cooperation usually takes long preparation times including the search, the evaluation and the integration of potential business partners. The longer the cooperation lasts, the stronger is the relationship and the trust that builds up due to shared experiences and resources. For this reason, partners proved to be reliable and cooperative are integrated into a 
permanent cooperation platform from which they can be quickly activated to realize a specific idea or product (Fig. 3). Thus the cooperation platform shows a more stable character, the activated elements (single enterprises) only make up a temporary stable network [8].

\subsection{Complementary Products and Services}

One special form of the virtual enterprise is the so-called complementary network, whose potentials are particularly beneficial to SME. On the basis of the traditional product spectrum, cooperation partners are sought whose products or services and competencies serve the same generic customer value - the so-called added value concept [5].

In this context the terms added value, complement and core competency are defined as follows: added value comes into existence when the combination of two complementary elements creates a value which the customer rates more highly than the two single values. In other words it is the phenomenon of the whole being greater than the sum of its parts [9]. A complement to a product or service is any other product or service which makes the whole more attractive to the customers that they prize it more highly when they also own the complement [5]. A core competency is understood as an integrated totality of technology, know-how and processes coordinated through organizational learning processes and in possession of which an enterprise can claim its position in the market. It must make an above-average contribution to the value perceived by the customer, and create potential access to a number of markets [10].

Cooperating partners can use the joined complementary core competencies to combine existing product and/or service solutions or, with a rising degree of trust, to generate new solutions. Well known examples for added-value solutions are cinemas and fast-food restaurants (independence), mobile phones and accessories (single dependence), hard- and software (interdependence). The customers reward the newly generated value, for they see it as a competition-free system solution from a single supplier.

\section{MANAGING COMPLEMENTARY NETWORKS}

The life-cycle of complementary networks divide into three distinct phases: the development of the added value idea, the setting-up of the network and the operational phase.

The easiest way of finding added value is the reaction to the already existing wishes of customers. The customer value can be gathered concretely 
from expressed needs. Creative enterprises go further and take advantage of the possibility to infer future customer needs from current trends and new technologies, thus anticipating customer value. The customer value established in these various ways confirms an added value concept and prompts the further development of the network.

The description of the added value concept at this point provides no information at all concerning the resources that have to be determined and combined in order to realise the concept. A systematic procedure here facilitates the transition from the added value concept to the desired complementary network and creates new tasks for additional partners alongside the product and service providers. Firstly, the desired individualisation of the product must be reduced to an acceptable degree. The aim to satisfy all the requirements of all the customers can only be fulfilled up to a certain point, beyond which the cost and effort increase exponentially.

Figure 4 shows an acceptance profile which translates the added value concept into a string of success factors for the wooing of purchasers, and mirrors the strategic organization of the network. Consultation with customers ascertains the individual needs and preferences of the known circle of customers.

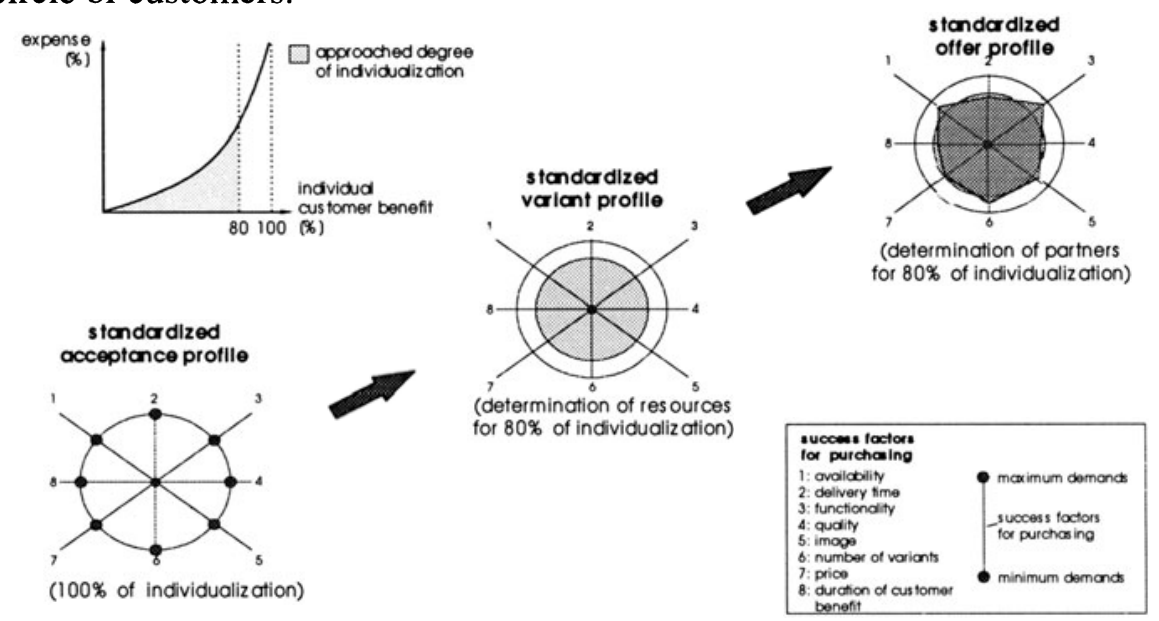

Figure 4: Conversion of the added value concept into a profile of success factors

The various opinions expressed about individual factors can now be used for a qualitative projection of the maximum requirements in the acceptance profile. The variant profile serves to determine what network resources are necessary. The degree to which the maximal requirements will be fulfilled is also decided upon. As a rule of thumb, an $80 \%$ fulfilment of requirements substantially saves effort and cost without severely affecting 
the number of potential customers. If the resource requirements established in the variant profile are assigned to specific network partners, the result could be a slight overshooting or falling short of the intended degree of fulfilment. It is therefore necessary to check whether the potential network partners' contribution will match the target requirement. Partners who meet this requirement or come very near are basically suitable for the network. With the aid of this information the network architect can now begin the negotiations in which those who can provide the competencies needed for the network are secured as partners. The continuously updated product and service profile supplies information as to how far the network partners' existing competencies match the catalogue of requirements. A poor level of correspondence between the variant profile and the product and service profile likewise indicates a problem for the future of the network.

In the operating phase, the most crucial consideration is the smooth coordination of products and services, thus to establish the proper relationships between the partners. These links concern not only logistics and the flow of materials and information but also the detailing of contractual relations. Order processing systems and marketing and sales activities are also planned during this phase.

\section{REALIZATION OF A SPECIFIC SOLUTION}

A successful example for a complementary network is the cooperation of a door manufacturer and electronic specialists. Bringing together complementary products and services allows them to realize the value added idea of creating an "intelligent door". This leads to a win-win situation for all participants in this network.

The customer benefits from the electronic door offering an added value compared to conventional door-systems. These doors are linked electronically and can thus show the way for a visitor to a certain room inside a building by opening the next door automatically. They can control access with integrated identification devices and can keep messages for persons inside the room, in case they are busy when somebody wants to enter.

During the phase of the product devolpment the participated enterprises profit from the exchange of their specific know-how and identifiy their own strenghts. By offering this unique product they open new market areas and come in contact with new groups of customers. This might give information about unserved customer needs and inspire the network partners for new product developments which an single enterprise is not able to create. 


\section{CONCLUSION}

The change of the general conditions in the postindustrial age has drastic effects on producing enterprises. The distinctive force of this development are primary the globalization process, the ongoing rapid developments of infrastructure systems and the rising requirements of the society. Especially the individualization of the human needs requires an increasing number of variants and innovations from enterprises.

In this paper a framework has been presented to design and manage Complementary Networks, which can realize specific needs or ideas in a temporarily activated network. It distinguishes itself from other network types by the conclusion of complementary core competencies of SME in order to generate a specific solution for the customer giving him a added value and leading to a better market situation for the involved enterprises.

\section{REFERENCES}

[1] Kinkel, S; Lay, G. (1998). Der Leistungsstand der deutschen Investitionsgüterindustrie, Fraunhofer Institut Systemtechnik und Innovationsforschung, Nr.11.

[2] Piller, F.: Kundenindividuelle Massenproduktion - Die Wettbewerbsstrategie der Zukunft, Hanser Verlag, München 1998

[3] Hamel, G.; Prahalad, C.K.: Wettlauf um die Zukunft, Überreuter Verlag, Wien 1995

[4] Sydow, J.: Strategische Netzwerke - Evolution und Organisation, Gabler Verlag, Wiesbaden 1992

[5] Nalebuff, B.; Brandenburger, A.: Competition - kooperativ konkurrieren: Mit der Spieltheorie zum Unternehmenserfolg, Campus Verlag, Frankfurt 1996

[6] Delphi '98: Studie zur globalen Entwicklung von Wissenschaft und Technik, Fraunhofer - Institut für Systemtechnik und Innovationsforschung.

[7] Bellmann, K.; Hippe, A.: Management von Unternehmensnetzwerken, Gabler Verlag, Wiesbaden 1996

[8] Schuh, G. et al.: Virtuelle Fabrik. Neue Marktchancen durch dynamische Netzwerke, Hanser Verlag, München 1998

[9] Haken, H. (1995). Erfolgsgeheimnisse der Natur - Synergetik: Die Lehre vom Zusammenwirken; Rowohlt Taschenbuch Verlag.

[10] Wildemann, H. (1996). Produktions- und Zuliefernetzwerke, gmft-Verlag, München. 